\title{
CUANDO EL PORTERO DEL EDIFICIO NO DABA NI LOS "BUENOS DÍAS": UNA FIGURA DESHUMANIZADA DE LA LITERATURA DEL TERROR ROJO
}

\author{
Marco da Costa \\ Izmir University of Economics, Turquía \\ marcodacosta1@hotmail.com
}

\begin{abstract}
RESUMEN: El artículo se centra en analizar a través de una muestra representativa de textos publicados durante la guerra civil por novelistas e intelectuales del bando nacional la figura del portero y el proceso de deshumanización y animalización que se llevaría a cabo con uno de los personajes de la retaguardia más estereotipados de la literatura sobre el Terror Rojo. Asimismo, se pretende resaltar cómo, detrás de la imagen peyorativa que ofrecerían autores como Tomás Borrás, Agustín de Foxá, Wenceslao Fernández Flórez, Alfredo Marqueríe, Félix Cuquerella, Edgar Neville o José-Vicente Puente sobre su profesión y funciones dentro del entramado para aniquilar al enemigo quintacolumnista, se escondía un ideario reaccionario, elitista, misoneísta y misógino para los que el portero simbolizaba la anarquía social y la desaparición de la pirámide jerárquica del antiguo régimen.
\end{abstract}

Palabras clave: portero, literatura falangista, Guerra Civil española, propaganda franquista, Terror Rojo, Madrid.

\section{WHEN THE DOORMAN OF THE BUILDING DID NOT EVEN SAY "GOOD MORNING": A DEHUMANIZED FIGURE OF THE LITERATURE OF RED TERROR}

ABSTRACT: The article focuses on analyzing, through a representative sample of texts published during the civil war by novelists and intellectuals of the national side, the figure of the doorman and the process of dehumanization and animalization that would be carried out with regard to one of the 
characters of the rearguard that was most stereotyped in the literature on the Red Terror. Likewise, it is intended to highlight how, behind the pejorative image offered by such authors as Tomás Borrás, Agustín de Foxá, Wenceslao Fernández Flórez, Alfredo Marqueríe, Félix Cuquerella, Edgar Neville, or José-Vicente Puente on the doorman's profession and functions within the framework to annihilate the fifth columnist enemy, a reactionary, elitist, misoneist, and misogynist ideology was hidden, for whom the doorman symbolized social anarchy and the disappearance of the hierarchical pyramid of the old regime.

Keywords: Doorman, Falangist Literature, Spanish Civil War, Francoist Propaganda, Red Terror, Madrid.

Recibido: 10 de febrero de 2020

Aceptado: 1 de julio de 2020

\section{Introducción}

Comentaba Tachín, seudónimo del periodista, abogado y escritor humorístico Joaquín Losada, que pasados los treinta años del final de la Guerra Civil española había llegado el momento de adoptar una cierta distancia desdramatizadora con respecto a la contienda bélica que desangró a todo el país. Precisamente esa actitud le condujo a publicar en la década de los setenta El humor en el Madrid rojo, volumen de breves estampas satíricas sobre la cotidianeidad de la capital durante la guerra que habría sido "impertinente" publicar poco después de 1939 "ante los cadáveres, aún tibios, de un millón de españoles muertos en lucha fratricida" ${ }^{1}$. En uno de los capítulos aparecía explicada la anécdota de la metamorfosis de aquel portero que, de la noche a la mañana, entre el 17 y 18 de julio, despedía a uno de los vecinos con un "hasta mañana, si Dios quiere, don Manuel" para saludarlo al día siguiente, inicio del levantamiento militar, con el protocolario "¡Salud, Manolo!"2 . La presencia del portero protagonizando el primero de aquellos cuadros costumbristas no resulta en ningún caso baladí dada la importancia que adquirió su figura a lo largo de la guerra y, principalmente, durante los primeros meses de una retaguardia madrileña a la que Francisco Casares describía como un "asilo de vagos y escuela de criminales" ${ }^{\prime \prime}$.

Nuestro objetivo, pues, será examinar este personaje de la tipología urbana guerracivilista $-y$ el modo en el que fue abordado de manera denigrante,

1. Tachín, El humor en el Madrid rojo, Madrid, Talleres Prensa Española, 1971, p. 10.

2. Ibídem, pp. 13-14.

3. Casares, F., La ciudad del humor y de la muerte, Madrid-Barcelona, Editorial Juventud, 1940, p. 36. 
caricaturesca e insultante ${ }^{4}$ - a partir de un corpus seleccionado de la literatura sobre el Terror Rojo publicado durante la guerra y la inmediata posguerra hasta la aparición en 1942 de La Causa General: la dominación roja en España ${ }^{5}$. El uso de aquel subgénero de la literatura fascista por parte del Departamento de Prensa y Propaganda de FET y de las JONS para demonizar al enemigo y legitimar, de paso, su poder sobre una población atemorizada por aquellas lecturas tendenciosas vino avalado por las principales plumas de la intelligentsia del bando nacional ${ }^{6}$. Estos autores -exiliados, fugitivos, refugiados en consulados

4. Lógicamente este trato respondería a su militancia en sindicatos y formaciones políticas de izquierdas. Sobre el estudio del portero de "derechas" como protector y víctima de la violencia de los comités revolucionarios durante la guerra civil así como de su condecoración en la posguerra por su conducta ejemplar véanse los trabajos de Oviedo Silva: "El enemigo a las puertas: porteros, violencia política y prácticas acusatorias en la posguerra madrileña", en Ferreira, A., Madeira, J. y Casanellas, P. (eds.), Violência política no século XX. Um balanço, Lisboa, Instituto de História Contemporânea, 2017, pp. 532-533 y "Nadie pase sin hablar al portero". El papel de los porteros en la vigilancia urbana, las prácticas informativas y las prácticas acusatorias en Madrid (1874-1945), University of Nottingham [Tesis Doctoral], 2019, pp. 183-195 y 323-333. Desde un punto de vista literario, aun no abundando en los textos consultados porteros falangistas que salvaran la vida de los inquilinos y vecinos del inmueble, se pueden encontrar breves referencias al portero afín a la rebelión militar en: El Caballero Audaz, Horas del Madrid rojo, Madrid, Ediciones Caballero Audaz, 1941, p. 158; Cuadrado Alonso, A., Mis diez meses de Madrid rojo, Melilla, Artes Gráficas Postal Exprés, 1938, p. 118; Foxá, A. de, Madrid de corte a checa, Madrid, Bibliotex, 2001 [1938], pp. 264 y 311; Neville, E., "Las muchachas de Brunete", Vértice, n. ${ }^{\circ} 12,1938$, p. 4 y Frente de Madrid, Madrid, EspasaCalpe, 1941, pp. 133 y 140.

5. Como bien indica Jiménez Herrera, la publicación de aquel compendio militar por parte del Ministerio de Justicia se haría notar, a partir de ese momento, en la literaturización del Terror Rojo: Los comités madrileños en 1936. Un análisis microhistórico de la represión, Universidad Complutense de Madrid [Tesis Doctoral], 2017, pp. 45-46. Con respecto al estudio de la literatura del Terror Rojo, orígenes y antecedentes históricos, literarios y cinematográficos, el tremendismo estilístico y la deshumanización de sus personajes prototípicos, pueden consultarse: Albert, M., "El tremendismo en la novela fascista", en Albert, M. (ed.), Vencer no es convencer. Literatura e ideología del fascismo español, Madrid-Frankfurt, Iberoamericana-Vervuert, 1998, pp. 101-108; García, H., "Relatos para una guerra. Terror, testimonio y literatura en la España nacional", Ayer 76, 2009, pp. 148-172; Mainer, J-C., "De Madrid a Madridgrado", en Albert, M. (ed.), Vencer no es convencer. Literatura e ideología del fascismo español, Madrid-Frankfurt, Iberoamericana-Vervuert, 1998, pp. 189-190; Martínez Cachero, J. M., Liras entre lanzas. Historia de la literatura nacional en la Guerra Civil, Madrid, Castalia, 2009, pp. 11-36; Santiáñez, N., "Cartografía crítica del fascismo español: Checas de Madrid de Tomás Borrás", Res publica 13-14, 2004, pp. 181-198; Sevillano, F., Rojos. La representación del enemigo en la Guerra Civil, Madrid, Alianza, 2007, pp. 43-61.

6. Para un estudio general de la literatura del bando nacional durante la guerra civil sigue siendo imprescindible consultar, a pesar de los diferentes puntos de vista expuestos, actitudes académicas y las intenciones metodológicas e ideológicas de sus respectivos autores, volúmenes como los de Mainer, J-C., Años de vísperas. La vida de la cultura en España (19311939), Madrid, Espasa Calpe, 2006, pp. 127-206 y Falange y literatura, Barcelona, RBA, 2013; Martínez Cachero, J. M., Liras entre lanzas. Historia de la literatura nacional en la Guerra Civil, ob. cit.; Rodríguez Puértolas, J., Historia de la literatura fascista española, vol. I, Madrid, Akal, 
y embajadas extranjeras o aposentados detrás de un escritorio en Salamanca, San Sebastián o Burgos ${ }^{7}$ - serán, a la postre, quienes, recurriendo a todo tipo de género literario, desde el diario a la literatura memorialística, pasando por la novela, el relato, la poesía y el teatro, ficcionalizarían al portero convirtiéndolo en uno de los máximos epítomes del Madridgrado surgido de la invectiva radiofónica de Queipo de Llano desde Radio Sevilla ${ }^{8}$.

Asimismo, cabe apuntar en estas palabras iniciales que, además del objeto en cuestión (portero) y el sujeto responsable de su (re)creación a partir del filtro distorsionador del postulado ideológico (autor), habría que tener en cuenta las referencias temporales y espaciales en las que se enmarcará el contexto en el que el portero aparecerá en escena, bien como secundario, bien como protagonista del drama expuesto. Por una parte, las andanzas y tropelías de este personaje tendrían lugar en los primeros meses de la guerra civil (verano-otoño de 1936) coincidiendo con una etapa anárquica y violenta que desembocaría en las trágicas sacas de Paracuellos y Torrejón de Ardoz ${ }^{9}$. Por otra parte, su papel como pieza del engranaje de la represión contra el enemigo estaría ligado, esencialmente, a los barrios donde vivía la mayoría de los burgueses, aristócratas y personalidades relacionadas con el mundo político de Falange y

1986, pp. 147-427; y Trapiello, A., Las armas y las letras. Literatura y guerra civil (1936-1939), Barcelona, Destino, 2014.

7. La literatura surgida del enclaustramiento en consulados y embajadas ha sido abordada por Martínez Cachero en dos artículos: "Literatura y cautiverio: el caso de las embajadas madrileñas durante la guerra civil", Archivum: Revista de la Facultad de Filología 37-38, 1987-1988, pp. 101-120 y "Miquelarena, un escritor 'en' la Guerra Civil", Razón Española 29, 1988, pp. 281-300. En el primero, analizaba cuatro muestras representativas como La vida inmóvil de Joaquín Calvo Sotelo, Meses de esperanza y lentejas de Samuel Ros, Una isla en el mar rojo de Wenceslao Fernández Flórez y El otro mundo de Jacinto Miquelarena. En el segundo, se centraba en la peripecia vital de este último escritor como refugiado y en la traslación literaria y testimonial de dicha experiencia en obras como El otro mundo, Cómo fui ejecutado en Madrid y la escapista colección Cuentos de humor.

8. "¿Qué pasa en Madridgrado? Ya sé que esta palabra, aun como parodia, es un poco bárbara. Denme ustedes otra que lo sea más. El General Queipo de Llano". Esta frase constaba en la portada interior de la primera edición que manejaremos del Madridgrado de Francisco Camba.

9. Referencias coetáneas a las sacas de Paracuellos y Torrejón de Ardoz se encuentran en El Duende Azul, Emocionario íntimo de un cautivo. Los cuatro meses de la Modelo, Madrid, Gráfica Administrativa, 1939, pp. 255-262, 296-299 y 329-343; Fernández Arias, A., Madrid bajo el Terror, Zaragoza, Librería General, 1937, pp. 248-253 y La agonía de Madrid, Zaragoza, Librería General, 1938, pp. 45, 63-64 y 94; Fonteriz, Luis de, Seis meses bajo el terror rojo en Madrid, Ávila, Tip. y Enc. de Senén Martín, 1937, pp. 82-89; Izaga y Ojembarrena, G. Arsenio de, Los presos de Madrid: recuerdos e impresiones de un cautivo en la España roja, Madrid, Imprenta Martosa, 1940, pp. 167-192 y 336-340; Miquelarena, J., Cómo fui ejecutado en Madrid, Ávila, Imprenta Católica Sigirano Díaz, 1937, pp. 38-42; y Schlayer, F., Matanzas en el Madrid republicano, Barcelona, Áltera, 2006 [1938], pp. 117-156. 
la CEDA. En este aspecto, los escritores erigirían al barrio de Salamanca como el escenario simbólico y mártir en el que actuaban con impunidad el portero y las turbas milicianas contra los miembros quintacolumnistas del ejército franquista $^{10}$. Como Miquelarena aseguraría con tristeza burlona, entre las cincuenta causas trágico-cómicas por las que se ejecutaba en aquel Madrid sovietizado estaba la de "vivir en el barrio de Salamanca"11.

\section{Su majestad, El portero}

\section{1. ¿Qué se hizo... del pueblo de Madrid?}

Muchos de los relatos y novelas en los que nos vamos a centrar situaban sus argumentos un poco antes del golpe militar. Era un buen momento para echar la mirada atrás y observar nostálgicamente que, antes de aquella "masa viscosa", "canalla", "roña emponzoñada" y "multitud sucia y grosera", calificativos utilizados por Neville a lo largo de su relato Las muchachas de Brunete, en la que se había convertido la ciudadanía de la capital de España, había existido un Madrid alegre, castizo y amable de clases populares que procedía del periodo alfonsino y la restauración monárquica. Todo aquel pueblo al que también pertenecía el portero había formado parte, sin el salvajismo y conflictividad social radicalizados con la llegada del régimen republicano, de un orden social inmutable y armónico durante siglos con el que habían crecido autores como el propio Edgar Neville, Agustín de Foxá o Giménez Caballero. La presencia física y ética de un Madrid republicano que no reconocían provocaba a muchos de

10. Sobre la represión miliciana en distritos madrileños como el de Salamanca, Villa de Vallecas, Puente de Vallecas, La Latina o Chamberí se ha ocupado el historiador Fernando Jiménez Herrera en una serie de estudios publicados en los últimos años que analizan la violencia en la retaguardia del Madrid de los comités y tribunales revolucionarios, responsables, durante los primeros meses de la guerra civil, de la gestión del orden público, los registros domiciliarios, las detenciones de vecinos y la impartición de la justicia popular. Destacar, entre los consultados, "El comité provincial de investigación pública a través de la documentación custodiada en el archivo general militar de Madrid", Hispania Nova. Revista de Historia Contemporánea 12, 2014; "Detrás del 'Terror Rojo'. Los Comités madrileños durante el verano-otoño de 1936", en Oviedo Silva, D. y Pérez-Olivares, A. (coords.), Una ciudad en guerra. Madrid, 1936-1948, Madrid, Los Libros de la Catarata, 2016, pp. 27-72; Los comités madrileños en 1936. Un análisis microhistórico de la represión, ob. cit., pp. 109-435; "Los comités madrileños como centros punitivos durante el otoño-invierno de 1936", en González Madrid, D., Ortiz Heras, M. y Pérez Garzón, J. (eds.), La Historia, lost in translation?, XIII Congreso de la Asociación de Historia Contemporánea, Cuenca, Ediciones de la Universidad de Castilla-La Mancha, 2017, pp. 675-686; “El Estado ante la revolución: Comités revolucionarios madrileños en la formación de una retaguardia antifascista (verano-otoño 1936)", en Moreno Seco, M., Fernández Sirvent, R. y Gutiérrez Lloret, R. (eds.), Del siglo XIX al XXI. Tendencias y debates, XIV Congreso de la Asociación de Historia Contemporánea, Universidad de Alicante, 20-22 de septiembre de 2018, pp. 1823-1836.

11. Miquelarena, J., Cómo fui ejecutado en Madrid, ob. cit., p. 67. 
aquellos escritores un profundo sentimiento de pérdida hacia una ciudad que, por culpa de la propaganda marxista, estaba pronta a desaparecer junto al madrileñismo goyesco de sus gentes. Los porteros se afiliaban a los sindicatos de la UGT $^{12}$, pertenecían a la Casa del Pueblo, se habían dejado imbuir por las ideas de Marx y Bakunin, escuchaban los acordes de la Internacional y comenzaban a discutir por ideas políticas con los vecinos de derechas, amenazando sin miramientos a curas y señoritos ${ }^{13}$.

La nostalgia por una Arcadia perdida les llevaría a utilizar un tono melancólico y plañidero en el que se mezclarían el tópico del ubi sunt por su infancia mancillada con reacciones propias del paternalismo de las clases altas, actitudes misoneístas, reaccionarismo ideológico y elitismo aristocrático. Todos estos sentimientos se canalizarían contra aquellas profesiones urbanas que, a partir del inicio de la Guerra Civil española, vieron llegado el momento de cumplir los sueños prometidos de poder revertir su situación y prosperar en el escalafón social. Dentro de aquel catálogo sociológico se incluían, además del portero - "figura especialmente denostada y temida" y "uno de los tipos más representativos del Madrid de la revolución"14 -, criadas, cocineras, doncellas, chóferes, mecánicos, camareros, limpiabotas, obreros, tranviarios, mozos de estación, carboneros, etc. Estos oficios proletarios a los que el comunismo había inoculado el odio de clase y la envidia social "por la sencilla razón de llevar una camisa limpia, un sombrero, una corbata"15 no pertenecían al verdadero pueblo y a la Nueva España que se pregonaba desde la otra línea del frente, compuesta por una nueva comunidad nacional de oficios artesanos como carpinteros, labriegos, arrieros, panaderos, pastores de ganado, herradores o prensadores de vides $^{16}$.

La mayoría de los textos, por tanto, se centrarían en denunciar el deseo indigno y ambicioso de estos personajes por aparentar lo que no eran y usurpar

12. En concreto, a la Sociedad de Porteros de Madrid y sus Contornos. Más información sobre este sindicato perteneciente a la UGT en Oviedo Silva, D., "El enemigo a las puertas: porteros, violencia política y prácticas acusatorias en la posguerra madrileña", ob. cit., p. 538 y "Nadie pase sin hablar al portero". El papel de los porteros en la vigilancia urbana, las prácticas informativas y las prácticas acusatorias en Madrid (1874-1945), ob. cit., pp. 48-51.

13. Baroja, P., Laura, Barcelona, Club Bruguera, 1981 [1939], p. 11; Iribarren, M., La ciudad, Madrid, Ediciones Españolas, 1939, pp. 100-106; Miquelarena, J., Cómo fui ejecutado en Madrid, ob. cit., p. 25; Otero del Pozo, S., España, inmortal, Valladolid, Afrodisio Aguado, 1936, pp. 9-12; y Pérez Madrigal, J., Tipos y sombras de la tragedia: Mártires y héroes. Bestias y farsantes, Ávila, Imprenta católica Sigirano Díaz, 1937, p. 55.

14. Castillo, F., Los años de Madridgrado, Madrid, Fórcola, 2016, p. 268.

15. El Tebib Arrumi, La gran tragedia de Madrid, Madrid, Ediciones España, 1939, p. 51.

16. Marquina, E., Los tres libros de España, Madrid-Cádiz, Establecimientos Cerón y Librería Cervantes, 1941, p. 8. 
el puesto, como los nuevos ricos de la revolución, de sus anteriores señores ${ }^{17}$. Esta pequeña toma de la Bastilla madrileña donde rodarían literalmente cabezas se trasladaría a los microcosmos carcelarios donde Pilar Millán Astray recreaba su experiencia en un reformatorio alicantino dedicando un poema a sus carceleras rojas, aquellas que "antes fuimos criadas, coristas o rameras, jahora somos las dueñas de nuestras prisioneras!"18. Asimismo, se les culparía de haber "ocupado", "violado" y "profanado" cientos y cientos de hogares de familias respetables y cristianas $^{19}$. Un delito que, por su cercanía con los vecinos, se achacaría especialmente a los porteros con quienes los milicianos de las Checas de Madrid bromeaban con darles el paseíllo por ser más explotadores que los propios burgueses y llegaban a desconfiar de su condición de proletarios porque eran unos

vagos, con calefacción y sin hacer más que leer el periódico, y alfombras, y a las diez, al teatro o a dormir... Propinas, trajes, cosas a granel; venga chupar de los inquilinos... Proletarios, ¿ de qué? Yo sí que era un proletario: ocho horas de manivela de tranvía... ${ }^{20}$.

\subsection{Al servicio de la revolución}

Desde el principio de la contienda, las tristemente célebres brigadas de milicianos, responsables del clima de inseguridad e impunidad del Madrid de los primeros meses, se dieron cuenta de la importancia de contar con la ayuda inestimable del portero a la hora de llevar a cabo las operaciones de represión contra aquellos miembros desafectos a la revolución. El conocimiento que tenía sobre sus vecinos en el periodo anterior a la guerra le proveería, llegado el momento, de un estatus muy destacado si hacemos caso al lugar que ocuparía en los textos contrarrevolucionarios. Así pues, como medida "para colaborar en la tarea de ir descubriendo los cobijos de tanto y tanto infeliz"21, se nombrarían unos Comités de Vecinos de los que el portero formaría parte en muchas ocasiones $^{22}$. En un poemario humorístico poco conocido de Domingo Romero, De la Checa a la Meca, se hacía burla precisamente de las dotes de mando de un

17. El Caballero Audaz, Horas del Madrid rojo, ob. cit., pp. 21-26; Carro, C., Paco y las duquesas, La Novela de "Vértice", 1939, p. 10; y Romero-Marchent, J., Soy un fugitivo, Valladolid, Librería Santarén, 1937, p. 31.

18. Millán Astray, P., Cautivas. 32 meses en las prisiones rojas, Madrid, Saturnino Calleja, 1940, p. 99.

19. Puente, J. V., Madrid recobrado, Madrid, Imp. Samarán, 1939, pp. 55-58.

20. Borrás, T., Checas de Madrid, Madrid, Escolar y Mayo editores, 2016 [1939], p. 91.

21. El Tebib Arrumi, La gran tragedia de Madrid, ob. cit., p. 50.

22. Oviedo Silva, D., "Denuncias y prácticas acusatorias en el Madrid bélico: los Comités de Vecinos", en Gómez Bravo, G. (coord.), Asedio. Historia de Madrid en la guerra civil (19361939), Madrid, Ediciones Complutense, 2018, pp. 367-401 y "Nadie pase sin hablar al porte- 
portero que, como el alcalde berlanguiano de Bienvenido, Mr. Marshall, iría repitiendo, para autoconvencerse del poder que detentaba, su cargo de "presidente del comité de vecinos y portero de esta finca desde comienzos del siglo"23.

Ese poder y el miedo que, en consecuencia, provocaría en la retaguardia republicana entre los partidarios de la rebelión militar se sustentaba en la facilidad con la que llamaba a la policía o a las brigadas nocturnas y del "Amanecer" para ejecutar una de sus principales funciones por las que sería repudiado en toda la literatura del periodo: la delación ${ }^{24}$. Su papel como delator que aparecerá en numerosas ocasiones entre los escritos sobre el Terror Rojo ${ }^{25}$ no solo le permitía cumplir con su deber al servicio de la revolución marxista sino también le posibilitaba situarse en una posición de prestigio, ascender socialmente en la pirámide revolucionaria y, de paso, enriquecerse a través del hurto de todos los objetos de valor de los pisos incautados por los milicianos. López de Medrano dejaría constancia en este párrafo de sus recuerdos "en el infierno" del sentimiento de repulsión que sentían estos autores ante tal cometido:

¡Los porteros! Otra calamidad venenosa al igual de las víboras. Por venganza o resentimientos, la denuncia era lanzada sobre el tranquilo hogar, que casi acto seguido era saqueado y llevados a la muerte sus moradores. Las denuncias se aceptaban sin pruebas de ninguna clase. Solamente bastaba hacerla. Toda clase de derechos sobre la propiedad o la misma vida habían quedado nulos. El terror imperaba por el terror $^{26}$.

Gracias a su posición inmejorable dentro de aquella atalaya en la que se había convertido la portería, otras actividades auxiliares que ejecutaría el portero

ro". El papel de los porteros en la vigilancia urbana, las prácticas informativas y las prácticas acusatorias en Madrid (1874-1945), ob. cit., pp. 150-151.

23. Romero, D., De la Checa a la Meca: cronicón del Madrid rojo, Madrid, Talleres Gráficos de C. Bermejo, 1939, pp. 231-243.

24. Sobre las habilidades delatoras del portero durante la guerra civil, que iban desde las confidencias y las acusaciones hasta la redacción de informes y la comparecencia como testigo en juicios véase Oviedo Silva, D., "Nadie pase sin hablar al portero". El papel de los porteros en la vigilancia urbana, las prácticas informativas y las prácticas acusatorias en Madrid (1874-1945), ob. cit., pp. 161-183.

25. Como pequeño botón de muestra de su función delatora pueden consultarse los volúmenes de Baroja, P., Laura, ob. cit., pp. 71 y 177; Borrás, T., Checas de Madrid, ob. cit., p. 101; El Caballero Audaz, Horas del Madrid rojo, ob. cit., pp. 28-29; Camba, F., Madridgrado, Madrid, Ediciones Española, 1939, p. 17; Cora, M. de, Retaguardia enemiga, Madrid, Altalena, 1984, p. 55; Fernández Arias, A., Madrid bajo el Terror, ob. cit., p. 236; Fernández Flórez, W., "Una isla en el mar rojo", Obras Completas, t. IV, Madrid, Aguilar, 1945, pp. 576-577; Foxá A. de, Madrid de corte a checa, ob. cit., p. 286; López de Haro, R., Adán, Eva y yo, Barcelona, Casa Editorial José Araluce, 1939, pp. 400 y 448; y Répide, P. de, Memorias de un aparecido, Madrid, Vassallo de Mumbert, 1977 [1937], p. 139.

26. López de Medrano, L., 986 días en el infierno, Madrid, Imp. y Lit. del Asilo de Huérfanos del Sagrado Corazón de Jesús, 1939, p. 84. 
a la perfección serían, por un lado, el espionaje ideológico a los vecinos y a todo aquel desconocido que entraba y salía del edificio y, por otro, el encargo de difundir bulos y propaganda marxista entre todos los acólitos, convencidos $u$ obligados, de las ventajas de penetrar en el "Paraíso soviético" ${ }^{27}$. Con respecto al primer punto por el que se sentía orgulloso este colectivo al haber comenzado a vigilar al cura, al falangista y al burgués mucho antes de que estallara la guerra, los porteros Ilegaron a formar una red de espionaje que provocaba auténtico pavor entre aquellos vecinos que permanecían ocultos ${ }^{28}$. Pero también serían los responsables, con la única intención de enardecer el odio hacia el enemigo, de hacerles creer que el ejército republicano había reconquistado San Sebastián, Burgos y Oviedo o que los "moros" comían carne humana y las "beatas" repartían caramelos envenenados a los niños ${ }^{29}$.

La multifuncionalidad del portero se diversificaría, si atendemos a los testimonios y fuentes literarias, a otros menesteres que certificaban la trascendencia relativa, o no, de esta figura en la represión contra el enemigo o la obsesión compartida por muchos de aquellos autores por magnificar su posición en aras de estigmatizar y desprestigiar a una revolución dirigida por gente tosca e ignorante. El portero estaría encargado, entre otros, de ejecutar los castigos si se cometían infracciones dentro del edificio ${ }^{30}$, de mandar al vecindario al sótano cuando la aviación enemiga bombardeaba el centro de Madrid ${ }^{31}$ o de vigilar que los vecinos tuvieran la radio encendida mientras sonaba el Himno de Rie$g^{32}$ y escucharan clandestinamente la emisora de Burgos y Salamanca ${ }^{33}$. Era un portero de la misma novela de Tomás Borrás quien se ocuparía, por ejemplo, de llamar la atención a los milicianos de que en la azotea se había emplazado

27. Precisamente la difusión de bulos, la celebración de victorias del bando sublevado o la exhibición de un espíritu derrotista fueron motivos para desenmascarar y acusar al portero de "derechas": Oviedo Silva, D., "Nadie pase sin hablar al portero". El papel de los porteros en la vigilancia urbana, las prácticas informativas y las prácticas acusatorias en Madrid (18741945), ob. cit., p. 193.

28. Borrás, T., Oscuro heroísmo, La Novela del Sábado, n. ${ }^{\circ}$ 2, Sevilla-Huelva, Editorial Católica Española, 1939, pp. 123 y 125 y Checas de Madrid, ob. cit., p. 91; Fernández Arias, A., Madrid bajo el Terror, ob. cit., pp. 52-53; y Fernández Flórez, W., "Una isla en el mar rojo", ob. cit., p. 596.

29. Fernández Arias, A., La agonía de Madrid, ob. cit., p. 30 y Borrás, T., Checas de Madrid, ob. cit., p. 97, respectivamente.

30. Fernández Arias, A., Madrid bajo el Terror, ob. cit., p. 83.

31. Romero, D., De la Checa a la Meca..., ob. cit., p. 232. Como señala Oviedo Silva en "Nadie pase sin hablar al portero". El papel de los porteros en la vigilancia urbana, las prácticas informativas y las prácticas acusatorias en Madrid (1874-1945), ob. cit., p. 157, uno de los métodos utilizados por las autoridades policiales para controlar la actuación y afección a la causa republicana del portero era imponerles la obligación, con la amenaza de sanciones en caso contrario, de habilitar los sótanos como refugio ante cualquier incursión aérea enemiga.

32. Fernández Arias, A., Madrid bajo el Terror, ob. cit., p. 84.

33. Borrás, T., Checas de Madrid, ob. cit., p. 103. 
un "paco" quintacolumnista ${ }^{34}$. Sus obligaciones por el triunfo de la revolución no tenían fin. Hasta incluso las fiestas navideñas eran un buen momento para demostrar su valía. Cuando llegara el instante de entregar un generoso donativo para los combatientes que estaban en el frente, todos los vecinos pasarían por la portería cuyo dueño y señor no dejaría de controlar a los inquilinos por si habían preparado un belén o se les encontraba en casa alguna figurita de barro o algo de musgo, hallazgos suficientes para llevarlos al "paseo fulminante" ${ }^{\prime 35}$.

En cuanto a este último aspecto, es bastante plausible afirmar que algunos porteros, inclinados todos los días a la delación, al espionaje y en busca del más mínimo error por parte del falangista emboscado, tuvieran voz y voto para decidir, o al menos demostrar, si un vecino era merecedor del famoso paseíllo ${ }^{36}$. En cualquier caso, habría que matizar que su involucración en el proceso para identificar y localizar al enemigo político "no equivalía a apretar el gatillo"37. Excelentes ejemplos literarios de las distintas fases, y siempre repetitivas, del paseo, desde que las Brigadas de los milicianos subían a registrar el piso y prendían al vecino en cuestión hasta su conducción a los lugares señalados para ejecutarlo, bien en las tapias de los cementerios, bien en zonas boscosas o cunetas de carreteras y caminos, se pueden encontrar en los poemas "La Brigada del Amanecer" de Agustín de Foxá38 y "Con cinturón de puñales" de Félix Cuquere$1 \mathrm{a}^{39}$, en la novela La ciudad del humor y de la muerte de Francisco Casares ${ }^{40} \mathrm{o}$ en el relato de Alfredo Marqueríe, Cuatro pisos y la portería ${ }^{41}$. El protagonismo del portero en toda aquella trágica secuencia tenía lugar principalmente en la fase inicial cuando el chivatazo les hacía saber a los milicianos que en un piso concreto de aquella finca se escondía un militar retirado, un sacerdote, un bur-

34. Ibídem, pp. 95-96. Los porteros, efectivamente, eran también responsables, ante las autoridades, de todos los disparos que procedían de las fincas urbanas en las que trabajaban: Oviedo Silva, D., "El enemigo a las puertas: porteros, violencia política y prácticas acusatorias en la posguerra madrileña", ob. cit., p. 539 y "Nadie pase sin hablar al portero". El papel de los porteros en la vigilancia urbana, las prácticas informativas y las prácticas acusatorias en Madrid (1874-1945), ob. cit., p. 151.

35. Camba, F., Madridgrado, ob. cit., pp. 170-171.

36. Este término que, al igual que paco con respecto a la acepción de "francotirador", formaría parte del argot guerracivilista indicaba, como era bien sabido, el asesinato sin juicio previo del enemigo a las afueras de las poblaciones y a horas intempestivas donde no existieran, por tanto, testigos incómodos.

37. Oviedo Silva, D., "Nadie pase sin hablar al portero". El papel de los porteros en la vigilancia urbana, las prácticas informativas y las prácticas acusatorias en Madrid (1874-1945), ob. cit., p. 171.

38. Foxá, A. de, Poesía (Antología 1926-1955), Sevilla, Renacimiento, 2005, pp. 109-111.

39. Cuquerella, F., Romances y episodios de la Revolución "Roja", Zaragoza, Librería General, 1940, pp. 23-26.

40. Casares, F., La ciudad del humor y de la muerte, ob. cit., pp. 38-51. 9-10.

41. Marqueríe, A., Cuatro pisos y la portería, Madrid, La Novela de "Vértice", 1940, pp. 
gués, un votante de la CEDA o un periodista que escribía en el $A B C^{42}$. Se darían pocos casos en los textos de porteros que acompañaban a las Brigadas hasta la puerta misma del piso ${ }^{43}$.

Habiendo analizado todos los datos aducidos hasta ahora, podemos resumir que la imagen del portero ofrecida por la mayoría de los autores consultados era la de un personaje mefistofélico con mucho poder que se situaba más allá del bien y del mal. Emilio Carrere llegaría a definirlo como "¡su Majestad la portera, la reina panderetona de la revolución!" ${ }^{44}$. En teoría, eran responsables, ante la autoridad judicial que había dictaminado en agosto de 1936 una orden privando al sereno de hacer uso a partir de las diez de la noche de las Ilaves para abrir los portales, de las arbitrariedades que pudieran cometer los milicianos quienes durante los primeros meses desoyeron la prohibición de hacer registros en los domicilios sin la presencia de un agente de la autoridad o de miembros de la Guardia de Asalto $^{45}$. De ahí que existían burgueses, como aseguraba Foxá, que "mimaban a los porteros y a las criadas" por la simple razón de que "eran los dueños de sus vidas" 46 o les imploraban para que les permitieran esconderse en un sótano o una buhardilla lejos del control de las patrullas nocturnas ${ }^{47}$.

Toda aquella aureola diabólica desplegada en la literatura del bando nacional sobre este auténtico arquetipo del Terror Rojo que con su autoridad en las fincas podía decidir sobre la vida y la muerte de los ciudadanos quedaría registrada, de nuevo, en una de aquellas cincuenta causas que citábamos al principio en las que Jacinto Miquelarena justificaba con humor negro el asesinato impune de una parte de la sociedad madrileña. Causa número 14: "Por haber discutido alguna vez con el portero" ${ }^{\prime 48}$.

\subsection{El "zeñó" y la "zeñora" Hyde}

En el apartado que sigue se intentará evidenciar cómo la descripción detaIlada que se realizaría en la literatura contrarrevolucionaria de la época en lo

42. Jacinto Miquelarena calificaría al $A B C$ de "periódico mártir" puesto que muchos de sus colaboradores más importantes (Ramiro de Maeztu, Víctor Pradera, Manuel Bueno y AlcaláGaliano) morirían asesinados en la Guerra Civil española (Miquelarena, J., El otro mundo, Burgos, Ediciones Castilla, 1938, p. 23).

43. Fernández Arias, A., Madrid bajo el Terror, ob. cit., p. 111.

44. Carrere, E., La ciudad de los siete puñales, La Novela del Sábado, n. 20, Madrid, Ediciones Españolas, 1939, p. 61.

45. Campoamor, C., La revolución española vista por una republicana, Sevilla, Renacimiento, 2018 [1937], pp. 161 y 176-177 y Oviedo Silva, D., "Nadie pase sin hablar al portero". El papel de los porteros en la vigilancia urbana, las prácticas informativas y las prácticas acusatorias en Madrid (1874-1945), ob. cit., pp. 152-153.

46. Foxá, A. de, Madrid de corte a checa, ob. cit., p. 304.

47. Fernández Arias, A., Madrid bajo el Terror, ob. cit., p. 103.

48. Miquelarena, J., Cómo fui ejecutado en Madrid, ob. cit., p. 65. 
que concernía al puesto adoptado por el portero en la retaguardia iría acompañada de un proceso deshumanizador del personaje que se ajustaba al modus operandi contra los buenos españoles. Vale la pena resaltarlo en coherencia con todo el desarrollo que hasta aquí se ha hecho puesto que, si bien es verdad que el desprecio experimentado por estos escritores se proyectó hacia aquellas profesiones urbanas comentadas anteriormente, afines a dejarse contagiar por la ideología marxista, el portero, sin duda alguna, se convertiría en uno de los objetivos con quien más se ensañarían las plumas falangistas del momento.

Esta deshumanización comportaba, en primer lugar, el escarnio y la degradación física del individuo. Estas descripciones manejaban, unas veces, recursos como la animalización cuando se le comparaba a "las víboras"49 y, otras, utilizaban una parte del cuerpo como metáfora simbólica de lo que significaba su figura calumniadora y delatora como en los casos en los que Tomás Borrás resaltaba su "oído fino", los "ojuelos maliciosos" y los "mudos ojos acusadores"50 o sus "orejas despegadas" empleaba en la presentación de aquellos porteros una tipología racial que por aquella época estaba siendo explotada por el antisemitismo nacionalsocialista en semanarios como Der Stürmer. De cualquier modo, tampoco era de extrañar el uso estereotipado del físico judío para la propia (des)calificación del portero con "jeta de perfil agudo", "nariz cortante y barbilla puntiaguda" y "rostro ganchudo" ${ }^{\prime 2}$ si se tiene en cuenta la identificación establecida entre el judaísmo y el marxismo no solo dentro de los parámetros ideológicos del Tercer Reich sino también en todas las campañas antijudías de la prensa católica y carlista durante el periodo republicano (Ellas, El Siglo Futuro, La Nación, Renacer, etc.) donde el masón, el judío y el comunista formaban todos ellos un conglomerado conspiratorio para minar los cimientos espirituales e históricos de la civilización occidental ${ }^{53}$.

Después de la caricaturización física, el portero era también un fiel acólito de la inmoralidad de aquella anti-patria descatolizada y anárquica. En todas sus apariciones resultaban seres poco de fiar, maliciosos, vengativos y envidiosos de la honradez e integridad de los señoritos siempre y cuando no estuvieran borrachos y alcoholizados que, en aquel caso, su actitud propendía hacia la

49. López de Medrano, L., 986 días en el infierno, ob. cit., p. 84.

50. Borrás, T., Checas de Madrid, ob. cit., pp. 104, 106 y 147.

51. Borrás, T., Oscuro heroísmo, ob. cit., p. 123.

52. Borrás, T., Checas de Madrid, ob. cit., pp. 106 y 123.

53. Álvarez Chillida, G., El antisemitismo en España. La imagen del judío (1812-2002), Madrid, Marcial Pons, 2002, pp. 175, 194-195, 277, 286 y 329; González, I., Los judíos y la Segunda República. 1931-1939, Madrid, Alianza, 2004, p. 268; Martín Sánchez, I., "La campaña antimasónica en El Siglo Futuro: la propaganda antijudía durante la Segunda República", Historia y Comunicación Social 4, 1999, pp. 75-87 y "La caricatura política durante la II República: El Debate, El Siglo Futuro y Gracia y Justicia", Brocar 34, 2010, pp. 208-212. 
agresión física. Su catadura moral quedaría precisada cuando la entrada de las tropas nacionales les hacía arrojar una careta que había escondido un carácter hipócrita, cobarde y temeroso ${ }^{54}$. Con la caída de Madrid, todavía existirían aquellos porteros, seleccionados entre los "más feroces", que se lamentaban de haber disimulado durante toda la contienda con el puño levantado para poder sobrevivir ${ }^{55}$. Estas actitudes autoexculpatorias mostradas por algunos porteros y porteras se desarrollarían con extensión en la inmediata posguerra cuando el Nuevo Estado, a través de un Juzgado Especial de Porteros ${ }^{56}$-muestra evidente de la importancia de esta figura de la que las autoridades franquistas no solo no se fiaban por su actuación durante la guerra sino que esperaban recabar información de la represión cometida en la retaguardia madrileña-, comenzó a estrechar el círculo sobre este colectivo con la ayuda de diferentes dispositivos de control: primero, vía edicto emitido por la Auditoría del Ejército de Ocupación que obligaba a comparecer a vecinos y vigilantes nocturnos; segundo, a través de declaraciones juradas, cuestionarios, formularios e interrogatorios por los que tendrían que pasar los porteros de fincas urbanas como parte del proceso depurativo al que se les sometió bajo la evaluación de antiguos inquilinos afines al nuevo régimen ${ }^{57}$.

Complemento, asimismo, de aquel comportamiento indigno de una persona civilizada era su modo de hablar y expresarse: otra de las piezas, manejadas hasta la saciedad, de aquel puzle esperpéntico y expresionista con el que se ridiculizaría el retrato humano del portero. Todos los autores incidirían en su

54. Borrás, T., Oscuro heroísmo, ob. cit., pp. 130-131 y Checas de Madrid, ob. cit., p. 103; Foronda, A. M. de, Nueve meses con los rojos en Madrid, Ávila, Imprenta Católica Sigirano Díaz, 1937, pp. 5-6; Iribarren, M., La ciudad, ob. cit., p. 167; y Répide, P. de, Memorias de un aparecido, ob. cit., p. 107.

55. Camba, F., Madridgrado, ob. cit., p. 401.

56. Oviedo Silva, D., "Nadie pase sin hablar al portero". El papel de los porteros en la vigilancia urbana, las prácticas informativas y las prácticas acusatorias en Madrid (1874-1945), ob. cit., pp. 286-291.

57. Información resumida a partir de las siguientes fuentes consultadas: Gómez Bravo, G. y Marco, J., La obra del miedo. Violencia y sociedad en la España franquista (1936-1950), Barcelona, Península, 2011, pp. 159-195; Oviedo Silva, D., "El enemigo a las puertas: porteros, violencia política y prácticas acusatorias en la posguerra madrileña", ob. cit., pp. 539-543; Oviedo Silva, D., "Nadie pase sin hablar al portero". El papel de los porteros en la vigilancia urbana, las prácticas informativas y las prácticas acusatorias en Madrid (1874-1945), ob. cit., pp. 253-323; Oviedo Silva, D. y Pérez-Olivares, A., “¿Un tiempo de silencio? Porteros, inquilinos y fomento de la denuncia en el Madrid ocupado", Stud. hist. H. ${ }^{a}$ cont. 34, 2016, pp. 301-331; Pérez-Olivares, A., "The City of Franco? Concerning Madrid, Public Order and Dictatorship's Repressive Nature", en Ferreira, A., Madeira, J. y Casanellas, P. (eds.), Violência política no século XX. Um balanço, Lisboa, Instituto de História Contemporânea, 2017, pp. 524-529; Pérez-Olivares, A., "Madrid, año de la victoria. Vivir y sobrevivir en una ciudad ocupada", Historia, Trabajo y Sociedad 8, 2017, pp. 119-126; Pérez-Olivares, A., La victoria bajo control: ocupación, orden público y orden social del Madrid franquista (1936-1948), Universidad Complutense de Madrid [Tesis Doctoral], 2017, pp. 175-238. 
lenguaje "blasfemo y pintoresco"58, acervo cultural y lingüístico común a toda aquella caterva de salvajes, del que sobresaldrían sus exabruptos, insultos y una larga lista de errores gramaticales con los que "la locura revolucionaria" también daba el paseíllo a "la lengua de Castilla" 59 .

Con todo, detrás de aquella preocupación por el "deje chungón" ${ }^{60}$ que empleaba una de las porteras de Checas de Madrid se encubría una mal disimulada aversión y desconsideración elitista y clasista -en este caso concreto, perteneciente al mundo lingüístico- de toda aquella plana mayor de escritores hacia la ignorancia demostrada por un grupo de infrahumanos que se caracterizaban al hablar por la fonética -poco culta- del habla andaluza o extremeña.

En este último párrafo se ha utilizado por primera vez el género gramatical femenino para referirnos al protagonista de este artículo. Hemos preferido, en este momento, singularizar a todas aquellas mujeres que ejercían la profesión de porteras porque, además de ocurrirles algo semejante en lo tocante a la imagen negativa ofrecida desde el otro bando contendiente (ambición social, función delatora, biotipo clásico del marxismo, incultura, etc.), su condición de mujer les iba a reportar otra retahíla de razones por las que su figura era tan despreciable, o más, que la de sus compañeros masculinos. Estas tenían que ver no tanto con actitudes misóginas, que también, como con la intención de la mayoría de aquellos peones intelectuales al servicio del Nuevo Estado franquista que, a partir de sus obras, expresarían abiertamente su deseo de revertir la situación ética, e incluso estética, de una mujer que con la llegada del sistema republicano había conseguido cotas nunca antes alcanzadas en España en términos de independencia y derechos. Así pues, el apoyo de estos escritores a los sublevados se basaba en la plena confianza de que solo los militares serían capaces de reinstaurar la jerarquía y el orden social, económico y moral en una sociedad en la que la nueva mujer del fascismo volvería al redil, tal y como lo expresaba el ideario nacionalsocialista de las tres K (Kinder, Küche, Kirche) ${ }^{61}$, olvidando, de este modo, los tiempos de "Las Sinsombrero", las tertulias literarias, el feminismo y las luchas por el sufragio universal.

Durante la guerra, la participación pública y activa de la mujer, tan denostada por los sectores retrógrados y contrarrevolucionarios de la sociedad republicana, no disminuiría, en ningún caso, tanto en el frente como en la retaguardia. El rol tradicional de la mujer sobre el que se sustentaría el patriarcado de la Nueva España colisionaba, pues, frontalmente con aquella "miliciana del mono abierto, de las melenas lacias, la voz agria y el fusil dispuesto a segar vidas por el malsano capricho de saciar su sadismo" o con "la pedante intelectual de

58. El Caballero Audaz, Horas del Madrid rojo, ob. cit., p. 58.

59. Répide, P. de, Memorias de un aparecido, ob. cit., p. 210.

60. Borrás, T., Checas de Madrid, ob. cit., p. 106.

61. "Niños, cocina e iglesia". 
izquierda, la estudiantilla fracasada, la empleada envidiosa del Jefe ${ }^{\prime \prime 2}$. El tercer círculo de este submundo dantesco surgido al compás de los acontecimientos bélicos lo conformaría un colectivo de (anti)mujeres que, como la portera, apoyaría la revolución desde sus áreas, casi siempre domésticas, de acción e influencia. Todas ellas transfiguradas por la literatura falangista en la reencarnación del rencor, la venganza, el crimen, la ignorancia, la antifeminidad, la sexualidad malsana o el sacrilegio hacia todo aquello que representaba, en contrapartida, la mujer católica, patriota y, sobre todo, buena madre.

Cerraremos este apartado haciendo mención, en particular, a dos volúmenes publicados el mismo año en los que las porteras asumían un papel más relevante en el argumento y que compendian el terror y la animadversión que inspiraba este personaje cada vez que aparecía o se le nombraba ${ }^{63}$. En el primero, Félix Cuquerella incluía en sus ingeniosos "episodios" una estampa poética escrita en agosto de 1936 y dedicada en exclusiva a una portera, de nombre Juana. Su retrato de "mujer-monstruo" con "ojos de ira, escupiendo las flemas del odio" respondía al perfil-arquetipo esperado de una portera con marido miliciano y tres hijos "rojos" en cuanto a pobreza cultural, demagogia propagandística y habilidad para encontrar y denunciar a los "facciosos" ${ }^{\prime \prime}$. El segundo al que nos referimos es el relato breve de Alfredo Marqueríe, Cuatro pisos y la portería, protagonizado por un matrimonio, el señor Venancio y la señora Eulalia, que se ocupaban de la portería de un edificio en un viejo barrio de Madrid. Aquí, como rezaba el título, vivía en cuatro pisos una serie de inquilinos que, como el joven falangista que estudiaba derecho, la solterona beata y el teniente coronel retirado, se iban a convertir, a partir del 18 de julio, en el objetivo delator y criminal de esta pareja fisgona y maledicente. El escritor les consagraba una de las descripciones más despiadadas escritas hacia aquel tipo de personajes nacidos "para una galería psiquiátrica donde se estudiarán deformaciones monstruosas (...) de los genios del mal". Unos seres esperpénticos, deformados moral y físicamente, con el cuerpo jorobado, los ojos "bastos y sin gracia, desgraciados, espiones", las narices achatadas "como las de ciertos sabuesos olisqueadores" y la lengua "sucia al servicio de la malicia, de la suposición dañina y felina"65. Unos seres, junto a otros adyuvantes proletarios que irán apareciendo en escena como el panadero, el cartero y el carbonero, a quienes Marqueríe responsabi-

62. Puente, J. V., Madrid recobrado, ob. cit., p. 50.

63. Sobre la imagen falseada, estereotipada y propagandística de la portera en la literatura del bando rebelde, intensificada por su condición de "roja" y "mujer", responde, entre otros, el caso real de Juana García Lago, portera en la calle Viriato n. 37 de Madrid, que, sin estar afiliada a ningún sindicato o formación política, acabaría siendo denunciada y encarcelada, una vez terminada la guerra, por la pertenencia al Partido comunista de su marido (Pérez-Olivares, A., La victoria bajo control: ocupación, orden público y orden social del Madrid franquista (1936-1948), ob. cit., pp. 198-200).

64. Cuquerella, F., Romances y episodios de la Revolución "Roja", ob. cit., pp. 83-86.

65. Marqueríe, A., Cuatro pisos y la portería, ob. cit., p. 4. 
lizaría del estallido de la revolución, cuya raison d'être, en definitiva, pasaba por odiar a la clase media, intrigar entre bambalinas como "conspiradores de zarzuela"66, diseminar propaganda marxista en el pueblo inocente de Madrid como ocurría con la joven criada del militar y dejar, como principal cometido, "una casa sin inquilinos, desalquilada, deshabitada por la revolución y la muerte" ${ }^{\prime \prime 67}$.

\section{La sinfonía del terror}

A partir de los textos se ha observado cómo el momento álgido de la justificación existencial del portero como pieza del engranaje aniquilador de la retaguardia quintacolumnista tenía lugar desde el instante en el que comunicaba a las autoridades competentes la existencia en el edificio de un enemigo del pueblo hasta que los milicianos aporreaban la puerta del piso en busca de dicho individuo para darle el paseo. Durante aquel breve lapso de tiempo el portero había realizado la más importante de sus tareas para colaborar en la victoria de la guerra y proclamar la llegada de la revolución marxista en la sociedad española.

Aun así, poco antes de haberse escuchado la detención de un coche en la puerta de la calle, aquellos escasos segundos en los que los vecinos esperaban con angustia la llegada de las temidas Brigadas se iban a convertir en uno de los trances más reproducidos, descritos y comentados por los artífices de la literatura del Terror Rojo. La mayoría de las apariciones del personaje del portero estarán encuadradas no solo en el contexto argumental de la irrupción de los milicianos sino también en un espacio simbólico en el cual una serie de elementos adquirirán nuevos significados inesperados.

A lo largo de toda esta secuencia los vecinos de Madrid, que por motivos ideológicos, laborales, políticos, religiosos o personales temían los registros domiciliarios y las detenciones de sus seres queridos, comenzaron a sentir auténtico pavor por una asociación de sonidos y ruidos que anteriormente al estallido de la guerra habrían sido considerados del todo inocentes en el marco rutinario de una vivienda. Esta concatenación acústica en la que cada instrumento obedecía cronológicamente las órdenes de los directores de esta particular sinfonía del terror -interpretada durante el silencio de la noche cuando todos aquellos componentes para provocar el pánico se magnificarían- advertía a los inquilinos de los pisos de la posible llegada de los milicianos. En algunos casos, la visita se presentaba de manera repentina pero, en otros, era el teléfono precursor quien "con sus llamadas, producía espanto"68.

66. Ibídem, p. 5.

67. Ibídem, p. 15

68. Fernández Arias, A., Madrid bajo el Terror, ob. cit., p. 54. 
El primer movimiento musical se iniciaba con el chirrido de las ruedas y el frenazo del coche deteniéndose frente al edificio delatado al que le acompañaba normalmente el uso de las bocinas para despertar al vecindario ya de por sí lo suficientemente desvelado. En el segundo movimiento el protagonismo recaía en el miedo provocado, bien por la parada del ascensor en un piso, bien por los pasos de los milicianos en la escalera, a los que Foxá describía en su comentado poema de "La Brigada del Amanecer" 69 como "un grito que queda en la garganta" y "cascada de palabras y de luces", respectivamente ${ }^{70}$. Otro poeta como Félix Cuquerella le dedicaba precisamente un poema a la situación de incertidumbre y desesperación en la que se encontraban unos vecinos mientras "sube el ascensor" ${ }^{\prime 71}$. Por último, aquel concierto terminaba con los acordes finales del timbre de la puerta. Un "ruido vibrante, horrísono, espantoso, el peor de cuantos allí podían oírse" que paralizaba el cuerpo y la mente y atemorizaba a los moradores más que los propios obuses de la aviación enemiga ${ }^{72}$.

El novelista Wenceslao Fernández Flórez, perseguido y asilado en embajadas extranjeras, expresaba su horrible soledad pendiente siempre "del timbre que suena, del ascensor que sube, de los coches que se detienen enfrente" ${ }^{\prime \prime 3}$. Objetos cotidianos, orgullo de la modernidad y el progreso, a los que la revolución convertiría en "tres sutiles agujas que el terror tuvo clavadas en las almas"74. El humorista gallego dejaría en la primera parte de su novela unas excelentes páginas mientras su yo ficticio se recluía en un piso de confianza para escapar de una muerte segura. Aunque la cita es larga, merece la pena transcribir este fragmento de ritmo tan cinematográfico ${ }^{75}$ como colofón y compendio final sobre la figura del portero enmarcada en el ambiente anárquico y violento de los

69. Sobre el papel colaboracionista de un grupo de porteros -que fomentaría en la posguerra la demonización de su figura en la literatura del Terror Rojo- en la violencia de la retaguardia dentro de las Milicias Populares de Investigación Criminal, conocidas popularmente como Brigada García Atadell, consúltese el excelente y original apartado de la tesis doctoral de Oviedo Silva, D., "Nadie pase sin hablar al portero". El papel de los porteros en la vigilancia urbana, las prácticas informativas y las prácticas acusatorias en Madrid (1874-1945), ob. cit., pp. 196-252.

70. Foxá, A. de, Poesía, ob. cit., p. 109.

71. Cuquerella, F., Romances y episodios de la Revolución "Roja", ob. cit., pp. 39-41.

72. Camba, F., Madridgrado, ob. cit., pp. 89 y 390. Por su parte, Fernández Flórez describiría al timbre como "aquel ruido estremecedor, hórrido como el de la trompeta de un paladín de Ariosto, más terrible que los que preceden a las náuseas de lava de un volcán" ("Una isla en el mar rojo", ob. cit., p. 663).

73. Fernández Flórez, W., "Una isla en el mar rojo", ob. cit., p. 603.

74. Ibídem, p. 648.

75. Una de las pocas películas consideradas propiamente falangista fue Rojo y negro (1942) de Carlos Arévalo que pondría en imagen todos los horrores descritos en la literatura sobre el Terror Rojo, desde los personajes de porteras repugnantes (Anselma) y milicianos salvajes hasta la filmación de registros domiciliarios e interrogatorios extrajudiciales en las checas de Madrid. 
meses iniciales de la guerra civil donde la ciudadanía aristocrática, burguesa, falangista y conservadora vivía atemorizada al paso de los coches de la CNT, UGT y la FAI y donde el sonido de un teléfono, un automóvil, un ascensor o un timbre no anunciaba la visita esperada de familiares y amigos:

Una tarde llegaron milicianos a nuestra casa. Erna los vio hablar brevemente con el portero y entrar, y entonces corrimos a espiar por los intersticios de la mirilla. El tubo de la escalera conducía hasta nosotros rumor de voces y pisadas, y, de pronto, el chasquido del contacto eléctrico del ascensor. Se oía el roce del cable en la polea y el zumbido del motor que hacía vibrar todo el cemento del edificio. Un chirrido, un piso, otro chirrido... Los contábamos entre el gruñir del artificio mal engrasado. El soplo leve y continuo que entraba por la rendija me enfriaba los ojos. El ascensor se acercaba. Vi surgir, primero, el resplandor de sus luces, y después su esmerilada cristalería, que dejaba transparentar sombras confusas. Y frente al rellano de nuestra puerta... se paró. Fue un momento en que todo pareció tener un aspecto decisivo. Abrióse la cancela de hierro y yo me aparté instintivamente de mi observatorio. Hice a Erna una señal confirmatoria y esperé a que llamasen. Se oyó aún cerrar el ascensor, y las pisadas de varios hombres, y el inconfundible ruido de las culatas de los fusiles al apoyarse en el suelo. Y, en seguida, un imperioso timbrazo ${ }^{76}$.

\section{Conclusiones}

Este trabajo pretende sumarse, desde un punto de vista estrictamente literario, a los recientes debates generados a raíz de una serie de estudios historiográficos en torno a la cultura de guerra durante la deflagración civil que estalló en 1936. Esta línea de investigación que cuenta con la participación, entre otros, de jóvenes historiadores como Jiménez Herrera, Oviedo Silva o Pérez-Olivares se ha centrado, como hemos ido apuntando a lo largo del artículo, en la actitud de la ciudadanía tanto en la violencia de la retaguardia republicana como en la posterior represión judicial implantada por las autoridades franquistas.

En nuestro caso, el objetivo se ha ceñido en analizar la figura ficcionalizada y literaturizada del portero de fincas urbanas y recuperar su importancia social

76. Fernández Flórez, W., "Una isla en el mar rojo", ob. cit., pp. 649-650. De la trascendencia, en general, del coche, el teléfono, las escaleras, el ascensor y el timbre como elementos sonoros durante el registro, la incautación y la represión dan cuenta también los volúmenes de Cora, M. de, Retaguardia enemiga, ob. cit., pp. 211-213; Cuquerella, F., Romances y episodios de la Revolución "Roja", ob. cit., pp. 23 y 80; Fernández Arias, A., Madrid bajo el Terror, ob. cit., pp. 54-55; y Répide, P. de, Memorias de un aparecido, ob. cit., pp. 134 y 286. 
(y simbólica) dentro de la mitología del Madrid rojo a partir de una amplia muestra representativa de textos publicados durante la Guerra Civil española o en los primeros años de la posguerra por autores falangistas y contrarrevolucionarios. Su asiduidad en aquella literatura memorialística y novelesca constituía la punta del iceberg más vilipendiado de todo un colectivo, caracterizado por la barbarie, la crueldad y la inmoralidad, que no pertenecía al verdadero pueblo español. Enfervorecidos tras años de propaganda marxista, la guerra les daría la oportunidad -siempre desde el punto de vista de una intelectualidad conservadora y elitista que apoyaría el golpe militar, más que por los aires revolucionarios que prometía el nacionalsindicalismo, en todo caso, por mantener su estatus privilegiado en la sociedad- de llevar a cabo un programa igualitario, fundamentado en la envidia y el rencor. Sus ideales se reducían a ocupar el puesto de sus antiguos directores, jefes y señoritos y a deshonrar y profanar los recuerdos y objetos de sus propietarios a través del robo y el pillaje durante los registros domiciliarios. En este sentido, conviene tener en cuenta que al desprecio elitista que sentirían los Agustín de Foxá, Edgar Neville, José-Vicente Puente, Tomás Borrás y compañía hacia aquella masa fanatizada e ignorante se le añadiría un componente misógino frente a la mujer moderna e independiente propugnada por el sistema republicano y caricaturizada durante la guerra en las figuras de las milicianas, criadas, doncellas y porteras al tiempo que se propagaban a los cuatro vientos las virtudes innatas de la mujer femenina de la Nueva España.

Otro aspecto que se infería de toda aquella literatura tenía que ver tanto con el relevante papel que se le otorgaría en la revolución al portero, y al resto de profesiones de índole urbano, como con el grado de responsabilidad y culpabilidad en el estallido y prolongación del conflicto bélico en la retaguardia. En el caso concreto del colectivo de los porteros, los textos encajaban, de algún modo, a este personaje como pieza fundamental en las fases iniciales del proceso de aniquilación del enemigo. Si bien, debido a la coyuntura de la guerra y al odio ideológico entre dos Españas irreconciliables, el portero quedaría sobredimensionado hasta extremos insospechados, el uso propagandístico de su figura no debería eximir, en cualquier caso, la existencia real de porteros que, aprovechando su posición estratégica en la portería y las ventajas materiales que se le presentaban, respondieran al estereotipo generalizado respecto a sus tareas colaboracionistas en el campo del espionaje y la delación. Esta premeditada exageración vendría acompañada por un proceso de ridiculización en la descripción biotipológica, sin olvidar su nivel lingüístico y cultural, para la que se recurriría a la tradición expresionista y esperpéntica, la caricatura literaria o a figuras retóricas como la animalización con el único propósito de desvanecer los contornos humanos de aquel individuo.

Por último, cabe hacer una reflexión final. Teniendo en cuenta, pues, que el portero se integró, con todos los honores, en el dramatis personae de un conglomerado de relatos fomentados y publicitados por la propaganda franquista para dañar la imagen de la República de cara al exterior y legitimar un poder 
sustentado en la lucha a muerte contra el comunismo foráneo, no resulta baladí preguntarse hasta qué punto influyó aquella literatura del bando nacional en los posteriores procesos judiciales (y depuratorios) que se llevaron a cabo contra aquel colectivo de trabajadores durante el primer franquismo. $Y$ hasta qué punto, finalmente, la imagen denigratoria y tendenciosa del portero exhibida en aquellos textos como un perverso sambenito mediatizó a las autoridades franquistas a la hora de confeccionar interrogatorios donde se les preguntaría directamente sobre su actuación personal durante la guerra, su afiliación a alguna formación política y su participación en algún tribunal o comité revolucionario.

\section{Bibliografía}

Albert, M., "El tremendismo en la novela fascista", en Albert, M. (ed.), Vencer no es convencer. Literatura e ideología del fascismo español, Madrid-Frankfurt, Iberoamericana-Vervuert, 1998, pp. 101-118.

Álvarez Chillida, G., El antisemitismo en España. La imagen del judío (18122002), Madrid, Marcial Pons, 2002.

Baroja, P., Laura, Barcelona, Club Bruguera, 1981 [1939].

Borrás, T., Oscuro heroísmo, La Novela del Sábado, n. ${ }^{2}$, Sevilla-Huelva, Editorial Católica Española, 1939.

Borrás, T., Checas de Madrid, Madrid, Escolar y Mayo editores, 2016 [1939].

El Caballero Audaz (seud. de José María Carretero), Horas del Madrid rojo, Madrid, Ediciones Caballero Audaz, 1941.

Camba, F., Madridgrado, Madrid, Ediciones Española, 1939.

Campoamor, C., La revolución española vista por una republicana, Sevilla, Renacimiento, 2018 [1937].

Carrere, E., La ciudad de los siete puñales, La Novela del Sábado, n. ${ }^{\circ}$ 20, Madrid, Ediciones Españolas, 1939.

Carro, C., (seud. de Conchita Montes), Paco y las duquesas, La Novela de "Vértice", 1939.

Casares, F., La ciudad del humor y de la muerte (Confesiones póstumas de un capitán de milicias), Madrid-Barcelona, Editorial Juventud, 1940.

Castillo, F., Los años de Madridgrado, Madrid, Fórcola, 2016.

Cora, M. de, Retaguardia enemiga, Madrid, Altalena, 1984.

Cuadrado Alonso, A., Mis diez meses de Madrid rojo, Melilla, Artes Gráficas Postal Exprés, 1938.

Cuquerella, F., Romances y episodios de la Revolución "Roja", Zaragoza, Librería General, 1940.

El Duende Azul (seud. de Antonio Cabanellas Camaño), Emocionario íntimo de un cautivo. Los cuatro meses de la Modelo, Madrid, Gráfica Administrativa, 1939. 
El Tebib Arrumi (seud. de Víctor Ruiz Albéniz), La gran tragedia de Madrid, Madrid, Ediciones España, 1939.

Fernández Arias, A., Madrid bajo el Terror, Zaragoza, Librería General, 1937.

Fernández Arias, A., La agonía de Madrid, Zaragoza, Librería General, 1938.

Fernández Flórez, W., "Una isla en el mar rojo", Obras Completas, t. IV, Madrid, Aguilar, 1945, pp. 547-838.

Fonteriz, Luis de, Seis meses bajo el terror rojo en Madrid, Ávila, Tip. y Enc. de Senén Martín, 1937.

Foronda, A. M. de, Nueve meses con los rojos en Madrid, Ávila, Imprenta Católica Sigirano Díaz, 1937.

Foxá, A. de, Madrid de corte a checa, Madrid, Bibliotex, 2001 [1938].

Foxá, A. de, Poesía (Antología 1926-1955), Sevilla, Renacimiento, 2005.

García, H., "Relatos para una guerra. Terror, testimonio y literatura en la España nacional", Ayer 76, 2009, pp. 143-176.

Gómez Bravo, G. y Marco, J., La obra del miedo. Violencia y sociedad en la España franquista (1936-1950), Barcelona, Península, 2011.

González, I., Los judíos y la Segunda República. 1931-1939, Madrid, Alianza, 2004.

Iribarren, M., La ciudad, Madrid, Ediciones Españolas, 1939.

Izaga y Ojembarrena, G. Arsenio de, Los presos de Madrid: recuerdos e impresiones de un cautivo en la España roja, Madrid, Imprenta Martosa, 1940.

Jiménez Herrera, F., "El comité provincial de investigación pública a través de la documentación custodiada en el archivo general militar de Madrid", Hispania Nova. Revista de Historia Contemporánea 12, 2014.

Jiménez Herrera, F., "Detrás del 'Terror Rojo'. Los Comités madrileños durante el verano-otoño de 1936", en Oviedo Silva, D. y Pérez-Olivares, A. (coords.), Una ciudad en guerra. Madrid, 1936-1948, Madrid, Los Libros de la Catarata, 2016, pp. 27-72.

Jiménez Herrera, F., Los comités madrileños en 1936. Un análisis microhistórico de la represión, Universidad Complutense de Madrid [Tesis Doctoral], 2017.

Jiménez Herrera, F., "Los comités madrileños como centros punitivos durante el otoño-invierno de 1936", en González Madrid, D., Ortiz Heras, M. y Pérez Garzón, J. (eds.), La Historia, lost in translation?, XIII Congreso de la Asociación de Historia Contemporánea, Cuenca, Ediciones de la Universidad de Castilla-La Mancha, 2017, pp. 675-686.

Jiménez Herrera, F., "El Estado ante la revolución: Comités revolucionarios madrileños en la formación de una retaguardia antifascista (verano-otoño 1936)", en Moreno Seco, M., Fernández Sirvent, R. y Gutiérrez Lloret, R. (eds.), Del siglo XIX al XXI. Tendencias y debates, XIV Congreso de la Asociación de Historia Contemporánea, Universidad de Alicante, 20-22 de septiembre de 2018, pp. 1823-1836. 
López de Haro, R., Adán, Eva y yo, Barcelona, Casa Editorial José Araluce, 1939. López de Medrano, L., 986 días en el infierno, Madrid, Imp. y Lit. del Asilo de Huérfanos del Sagrado Corazón de Jesús, 1939.

Mainer, J-C., "De Madrid a Madridgrado", en Albert, M. (ed.), Vencer no es convencer. Literatura e ideología del fascismo español, Madrid-Frankfurt, Iberoamericana-Vervuert, 1998, pp. 181-198.

Mainer, J-C., Años de vísperas. La vida de la cultura en España (1931-1939), Madrid, Espasa Calpe, 2006.

Mainer, J-C., Falange y literatura, Barcelona, RBA, 2013.

Marqueríe, A., Cuatro pisos y la portería, Madrid, La Novela de "Vértice", 1940.

Marquina, E., Los tres libros de España, Madrid-Cádiz, Establecimientos Cerón y Librería Cervantes, 1941.

Martín Sánchez, I., "La campaña antimasónica en El Siglo Futuro: la propaganda antijudía durante la Segunda República", Historia y Comunicación Social 4, 1999, pp. 73-87.

Martín Sánchez, I., "La caricatura política durante la II República: El Debate, El Siglo Futuro y Gracia y Justicia", Brocar 34, 2010, pp. 203-242.

Martínez Cachero, J. M., "Literatura y cautiverio: el caso de las embajadas madrileñas durante la guerra civil", Archivum: Revista de la Facultad de Filología 37-38, 1987-1988, pp. 101-120.

Martínez Cachero, J. M., "Miquelarena, un escritor 'en' la Guerra Civil", Razón Española 29, 1988, pp. 281-300.

Martínez Cachero, J. M., Liras entre lanzas. Historia de la literatura nacional en la Guerra Civil, Madrid, Castalia, 2009.

Millán Astray, P., Cautivas. 32 meses en las prisiones rojas, Madrid, Editorial Saturnino Calleja, 1940.

Miquelarena, J., Cómo fui ejecutado en Madrid, Ávila, Imprenta Católica Sigirano Díaz, 1937.

Miquelarena, J., El otro mundo, Burgos, Ediciones Castilla, 1938.

Neville, E., "Las muchachas de Brunete", Vértice 12, 1938, pp. 1-5.

Neville, E., Frente de Madrid, Madrid, Espasa-Calpe, 1941.

Otero del Pozo, S., España, inmortal, Valladolid, Afrodisio Aguado, 1936.

Oviedo Silva, D., "El enemigo a las puertas: porteros, violencia política y prácticas acusatorias en la posguerra madrileña", en Ferreira, A., Madeira, J. y Casanellas, P. (eds.), Violência política no século XX. Um balanço, Lisboa, Instituto de História Contemporânea, 2017, pp. 531-545.

Oviedo Silva, D., "Denuncias y prácticas acusatorias en el Madrid bélico: los Comités de Vecinos", en Gómez Bravo, G. (coord.), Asedio. Historia de Madrid en la guerra civil (1936-1939), Madrid, Ediciones Complutense, 2018, pp. 367-401. 
Oviedo Silva, D., "Nadie pase sin hablar al portero". El papel de los porteros en la vigilancia urbana, las prácticas informativas y las prácticas acusatorias en Madrid (1874-1945), University of Nottingham [Tesis Doctoral], 2019.

Oviedo Silva, D. y Pérez-Olivares, A., "¿Un tiempo de silencio? Porteros, inquilinos y fomento de la denuncia en el Madrid ocupado", Stud. hist. H. ${ }^{a}$ cont. 34, 2016, pp. 301-331.

Pérez Madrigal, J., Tipos y sombras de la tragedia: Mártires y héroes. Bestias y farsantes, Ávila, Imprenta católica Sigirano Díaz, 1937.

Pérez-Olivares, A., "The City of Franco? Concerning Madrid, Public Order and Dictatorship's Repressive Nature", en Ferreira, A., Madeira, J. y Casanellas, P. (eds.), Violência política no século XX. Um balanço, Lisboa, Instituto de História Contemporânea, 2017, pp. 519-530.

Pérez-Olivares, A., La victoria bajo control: ocupación, orden público y orden social del Madrid franquista (1936-1948), Universidad Complutense de Madrid [Tesis Doctoral], 2017.

Pérez-Olivares, A., "Madrid, año de la victoria. Vivir y sobrevivir en una ciudad ocupada", Historia, Trabajo y Sociedad 8, 2017, pp. 113-131.

Puente, J. V., Madrid recobrado, Madrid, Imp. Samarán, 1939.

Répide, P. de, Memorias de un aparecido, Madrid, Vassallo de Mumbert, 1977 [1937].

Rodríguez Puértolas, J., Historia de la literatura fascista española, vol. I, Madrid, Akal, 1986.

Romero, D., De la Checa a la Meca: cronicón del Madrid rojo, Madrid, Talleres Gráficos de C. Bermejo, 1939.

Romero-Marchent, J., Soy un fugitivo, Valladolid, Librería Santarén, 1937.

Santiáñez, N., "Cartografía crítica del fascismo español: Checas de Madrid de Tomás Borrás", Res publica 13-14, 2004, pp. 181-198.

Schlayer, F., Matanzas en el Madrid republicano, Barcelona, Áltera, 2006 [1938].

Sevillano, F., Rojos. La representación del enemigo en la Guerra Civil, Madrid, Alianza, 2007.

Tachín (seud. de Joaquín Losada), El humor en el Madrid rojo, Madrid, Talleres Prensa Española, 1971.

Trapiello, A., Las armas y las letras. Literatura y guerra civil (1936-1939), Barcelona, Destino, 2014. 